Pacific Journal of Mathematics

PERTURBATION THEORY FOR GENERALIZED FREDHOLM 


\title{
PERTURBATION THEORY FOR GENERALIZED FREDHOLM OPERATORS
}

\author{
S. R. CARAdus
}

\begin{abstract}
Successful development of the theory of Fredholm and semi-Fredholm operators and a general recognition of the importance of the subject provides an impetus for the study of various generalizations. In this paper, a study is made of operators whose ranges and null spaces are closed complemented subspaces. In particular, if $T$ is such an operator, a rather general sufficient condition is obtained to ensure that $T-U$ is of the same kind. This perturbation theorem includes, as special cases, previous results due to Dieudonné, Saphar, and Crownover.
\end{abstract}

1. Definitions and basic properties. If $X$ is a Banach space, write $B(X)$ to denote the space of continuous linear operators defined on $X$. We shall study the class of operators $T$ in $B(X)$ which have the property that both the null space $N(T)$ and the range $R(T)$ are closed complemented subspaces of $X$. This class of operators contains all the Fredholm operators and will therefore be called the generalized Fredholm operators, denoted $G F(X)$. We observe immediately that when $X$ is a Hilbert space, then $G F(X)$ consists merely of those operators which have closed range and that in all cases, $G F(X)$ contains all projections. Such an observation would discourage one's optimism about paralleling the theory of Fredholm operators to any reasonable extent. However, the fact that $G F(X)$ has already been studied under another guise encourages further scrutiny; more precisely, we introduce the notion of generalized inverse as follows: an operator $T$ in $B(X)$ is said to have a generalized inverse $S$ in $B(X)$ if the following equations are valid:

$$
\begin{gathered}
T S T=T \\
S T S=S .
\end{gathered}
$$

The above notion has attracted a great deal of interest in the finite dimensional case and has been the subject of at least three recent monographs ([3], [8], [9]). It is perhaps appropriate to remark that conditions (1) and (2) are usually augmented by others leading to a variety of notions with a rather variable terminology. Some extensions to infinite dimensional situations have been considered by F. J. Beutler [2], and W. T. Reid [10] and others. Particular attention should be paid to the early paper of Atkinson [1] in which he calls operators satisfying (1) and (2) relatively regular and derives 
many of their properties. The fact that generalized Fredholm operators are exactly those which have a generalized inverse has been known for a long time but since its proof is usually given in a finite dimensional setting, it is included here in the general case.

LEMma. T is a generalized Fredholm operator if and only if $T$ has a generalized inverse.

Proof. Let $T$ belong to $G F(X)$ so that there exist closed subspaces $X_{1}$ and $X_{2}$ such that $X$ can be decomposed as $N(T) \oplus X_{1}$ and $R(T) \oplus X_{2}$. Let $P$ denote the projection onto $R(T)$ parallel to $X_{2}$. Now write $T_{1}$ for the restriction of $T$ to $X_{1}$ so that $T_{1}$ has a continuous inverse defined on $R(T)$. Therefore, $T_{1}^{-1} P$ is well defined in $B(X)$; it is easy to check that $T_{1}^{-1} P$ is a generalized inverse of $T$.

Conversely, if $S$ is a generalized inverse of $T$, then equations (1) and (2) imply that TS is a projection of $X$ onto $R(T)$ parallel to $N(S)$ and $I-S T$ is a projection of $X$ onto $N(T)$ parallel to $R(S)$. Hence $T$ belongs to $G F(X)$.

2. Perturbation theory. In general, $G F(X)$ is not an open set nor is it stable under compact perturbations. To see this, we recall a construction due to R. J. Whitley ([7], V.2.6): if $T$ is an operator with closed range of infinite codimension and $N(T)$ is infinite dimensional, then it is possible to construct a compact operator $B$ such that $T+\lambda B$ does not have closed range for any $\lambda \neq 0$. The perturbation problem which we study therefore, gives a sufficient condition on the operators concerned and our result will include various interesting special cases including those of Saphar [11] and Crownover [4].

THEOREM. Let $T$ be a generalized Fredholm operator defined on Banach space $X$ and suppose that $S$ is a generalized inverse of $T$. Let $U$ be an operator in $B(X)$ such that $\|U\|<\|S\|^{-1}$ and (I$U S)^{-1} U$ maps $N(T)$ into $R(T)$. Then $S(I-U S)^{-1}$ and $(I-S U)^{-1} S$ are equal and their common value $V$ is a generalized inverse of $T-U$. Moreover, $N(T-U)$ is a complementary subspace to $R(S)$ and $R(T-U)$ is a complementary subspace to $N(S)$ so that $N(T-U)$ and $R(T-U)$ are linearly homeomorphic, respectively to $N(T)$ and $R(T)$.

Proof. Since $\|U\|<\|S\|^{-1}$, the Neumann series of $(I-U S)^{-1}$ and $(I-S U)^{-1}$ converge and it is easy to see, by writing them out, that $S(I-U S)^{-1}$ and $(I-S U)^{-1} S$ are equal. Then 


$$
\begin{aligned}
V(T-U) V & =(I-S U)^{-1} S(T-U) S(I-U S)^{-1} \\
& =(I-S U)^{-1}(S T S-S U S)(I-U S)^{-1} \\
& =(I-S U)^{-1} S(I-U S)(I-U S)^{-1} \\
& =V .
\end{aligned}
$$

Now consider

$$
\begin{aligned}
T-U-(T-U) V(T-U) & =\left[I-(T-U) S(I-U S)^{-1}\right](T-U) \\
& =[I-U S-(T-U) S](I-U S)^{-1}(T-U) \\
& =(I-T S)(I-U S)^{-1}(T-U S T+U S T-U) \\
& =(I-T S)(I-U S)^{-1}[(I-U S) T+U(S T-I)] \\
& =(I-T S)(I-U S)^{-1} U(S T-I) \\
& =0
\end{aligned}
$$

if $(I-U S)^{-1} U$ maps $R(S T-I)$ into $N(I-T S)$. But, as noted in the proof of the Lemma, $R(S T-I)$ is $N(T)$ and $N(I-T S)$ is $R(T)$. Hence the first part of the proof is complete.

Now

$$
R(V)=R\left[S(I-U S)^{-1}\right]=R(S)
$$

so that

$$
X=N(T-U) \oplus R(V)=N(T-U) \oplus R(S)
$$

Similarly

$$
N(V)=N\left[(I-S U)^{-1} S\right]=N(S)
$$

so that

$$
X=R(T-U) \oplus N(V)=R(T-U) \oplus N(S) .
$$

Corollaries. 1. If $N(U) \supseteqq N(T)$ or $R(U) \subseteq R(T)$ with $\|U\| \leqq$ $\|S\|^{-1}$, then $T-U$ is generalized Fredholm.

Proof. If $N(U) \supseteqq N(T)$, then $(I-U S)^{-1} U$ maps $N(T)$ onto $\{0\}$. If $R(U) \subseteq R(T)$, then we observe that $(I-U S)^{-1} U$ can be written as $U(I-S U)^{-1}$ so that its range lies inside $R(U)$ and hence it maps $N(T)$ into $R(T)$.

2. The class of left invertible operators is given by $\{T \in G F(X)$ : $N(T)=\{0\}\}$; the class of right invertible operators is given by $\{T \in G F(X): R(T)=X\}$. Hence from Corollary 1, we obtain the wellknown result (Dieudonné [5]) that these classes are open sets in $B(X)$.

3. Suppose $T$ is a generalized Fredholm operator with $R(T) \supseteqq$ $N(T)$. Let $M$ be closed subspace of $X$ such that $R(T) \supseteqq M \supseteqq N(T)$ 
and $T M=M$. Then if $U M \subseteq M$ and $\|U\|<\|S\|^{-1}$, the conclusions of the Theorem are valid.

Proof. (TS) $M=(T S T) M=T M=M$ so that $S M \cong T^{-1} M$. Now if $m \in T^{-1} M$, then $T m \in M=T M$ so that there exists $m^{\prime} \in M$ such that $T m=T m^{\prime}$. But $m-m^{\prime} \in N(T) \subseteq M$ so that $m \in M$. Hence $T^{-1} M \subseteq M$. Therefore, $S M \subseteq M$ and so $(I-U S)^{-1} U M \subseteq M$. Hence we can write

$$
\begin{aligned}
R\left[(I-T S)(I-U S)^{-1} U(S T-I)\right] & =(I-T S)(I-U S)^{-1} U N(T) \\
& \leqq(I-T S)(I-U S)^{-1} U M \\
& \leqq(I-T S) M \\
& \leqq(I-T S) R(T)=\{0\}
\end{aligned}
$$

Hence the result.

4. If $R\left(T^{n}\right) \supseteqq N(T)$ for each $n$ and all $R\left(T^{n}\right)$ are closed, then $M=\bigcap_{1}^{\infty} R\left(T^{n}\right)$ satisfies the conditions of Corollary 3. This gives Saphar's main result in [11] (Théorèmes 1 and 2).

5. If $N(T)=\{0\}$ and $R(T)$ has codimension 1 (and is therefore closed) and $\bigcap_{1}^{\infty} R\left(T^{n}\right)=\{0\}$, then Crownover [3] calls such an operator a shift on $X$. Clearly, for any such shift, all $R\left(T^{n}\right)$ are closed since $T$ is Fredholm. Therefore, shifts satisfy the condition of Corollary 4. Crownover's Theorem 2 ([4], p. 236) considers $T-\lambda I$ when $T$ is a shift and derives a result essentially the same as ours in this very special case.

\section{REFERENCES}

1. F. V. Atkinson, On relatively regular operators, Acta Scient. Math., (Szeged) 15 (1) (1953), 38-56.

2. F. J. Beutler, The operator theory of the pseudo-inverse, J. Math. Anal. Appl., X (1965), 451-470, 471-493.

3. T. L. Boullion and P. L. Odell, Generalized Inverse Matrices, Wiley-Interscience, N.Y. 1971.

4. R. M. Crownover, Commutants of shifts on Banach spaces, Michigan Math. J., 19 (1972), 233-247.

5. J. Dieudonné, Sur les homomorphismes d'espaces normés, Bull. Sc. Math., Serie 2, t67, (1943), $1^{\text {re }}$ partie, 72-84.

6. I. C. Gokhberg and M. G. Krein, The basic propositions on defect numbers, root numbers and indices of linear operators, Amer. Math. Soc. Translations, 2 (13), (1960), 185-264.

7. S. Goldberg, Unbounded Linear Operators, McGraw-Hill, N.Y., 1966.

8. R. M. Pringle and A. A. Rayner, Generalized Inverse Matrices with Applications to Statistics, Griffin, 1971.

9. M. M. Rao and S. K. Mitra, The Generalized Inverse of a Matrix and its Applications, Wiley, 1971. 
10. W. T. Reid, Generalized Inverses of Differential and Integral Operators, Proceeding of the Symposium on Theory and Applications of Generalized Inverse of Matrices, Lubbock, Texas, (1968), 1-25.

11. P. Saphar, Contribution a l'étude des applications lineaires dans un espace de Banach, Bull. Soc. Math. de France, 92 (1964), 363-384.

Received October 15, 1973. Research partly supported by NRC Operating Grant A 3985.

QUeEn's UNIVERSity, Kingston, ONTARIO 



\section{PACIFIC JOURNAL OF MATHEMATICS}

EDITORS

RICHARD ARENS (Managing Editor)

University of California

Los Angeles, California 90024

R. A. Beaumont

University of Washington

Seattle, Washington 98105

J. DugundJI

Department of Mathematics

University of Southern California

Los Angeles, California 90007

D. Gilbarg and J. Milgram

Stanford University

Stanford, California 94305

\section{ASSOCIATE EDITORS}

E. F. BECKENBACH

B. H. NeumanN

F. WOLF

K. YOSHIDA

\section{SUPPORTING INSTITUTIONS}

UNIVERSITY OF BRITISH COLUMBIA CALIFORNIA INSTITUTE OF TECHNOLOGY

UNIVERSITY OF CALIFORNIA

MONTANA STATE UNIVERSITY

UNIVERSITY OF NEVADA

NEW MEXICO STATE UNIVERSITY

OREGON STATE UNIVERSITY

UNIVERSITY OF OREGON

OSAKA UNIVERSITY

\author{
UNIVERSITY OF SOUTHERN CALIFORNIA \\ STANFORD UNIVERSITY \\ UNIVERSITY OF TOKYO \\ UNIVERSITY OF UTAH \\ WASHINGTON STATE UNIVERSITY \\ UNIVERSITY OF WASHINGTON \\ $\stackrel{*}{*} \stackrel{*}{*}{ }^{*}{ }^{*}{ }^{2}$ AMERICAN MATHEMATICAL SOCIETY \\ NAVAL WEAPONS CENTER
}




\section{Pacific Journal of Mathematics}

\section{Vol. 52, No. $1 \quad$ January, 1974}

David R. Adams, On the exceptional sets for spaces of potentials ............ 1

Philip Bacon, Axioms for the Čech cohomology of paracompacta ............ 7

Selwyn Ross Caradus, Perturbation theory for generalized Fredholm operators ..... 11

Kuang-Ho Chen, Phragmén-Lindelöf type theorems for a system of nonhomogeneous equations ............................ 17

Frederick Knowles Dashiell, Jr., Isomorphism problems for the Baire classes .......

M. G. Deshpande and V. K. Deshpande, Rings whose proper homomorphic images are right subdirectly irreducible . . . . . . . . . . . . . . . . . . . . . . . . .

Mary Rodriguez Embry, Self adjoint strictly cyclic operator algebras .............

Paul Erdős, On the distribution of numbers of the form $\sigma(n) / n$ and on some related

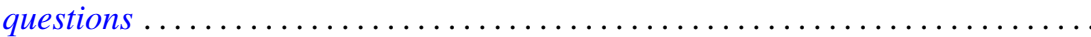

Richard Joseph Fleming and James E. Jamison, Hermitian and adjoint abelian

operators on certain Banach spaces ............................

Stanley P. Gudder and L. Haskins, The center of a poset .................. 85

Richard Howard Herman, Automorphism groups of operator algebras . . . ........

Worthen N. Hunsacker and Somashekhar Amrith Naimpally, Local compactness of families of continuous point-compact relations ....................

Donald Gordon James, On the normal subgroups of integral orthogonal groups ....

Eugene Carlyle Johnsen and Thomas Frederick Storer, Combinatorial structures in

loops. II. Commutative inverse property cyclic neofields of prime-power

order.

Ka-Sing Lau, Extreme operators on Choquet simplexes . . . . . . . . . . . . . . 129

Philip A. Leonard and Kenneth S. Williams, The septic character of 2, 3, 5 and $7 \ldots 143$

Dennis McGavran and Jingyal Pak, On the Nielsen number of a fiber map ........ 149

Stuart Edward Mills, Normed Köthe spaces as intermediate spaces of $L_{1}$ and

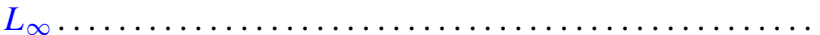

Philip Olin, Free products and elementary equivalence. .

Louis Jackson Ratliff, Jr., Locally quasi-unmixed Noetherian rings and ideals of the principal class.

Seiya Sasao, Homotopy types of spherical fibre spaces over spheres ...

Helga Schirmer, Fixed point sets of polyhedra ...

Kevin James Sharpe, Compatible topologies and continuous irreducible

representations.

Frank Siwiec, On defining a space by a weak base . . . . . . . . . . . . . . . 233

James McLean Sloss, Global reflection for a class of simple closed curves ....... 247

M. V. Subba Rao, On two congruences for primality . .

Raymond D. Terry, Oscillatory properties of a delay differential equation of even

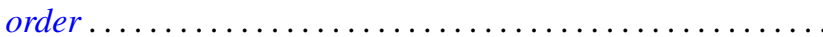

Joseph Dinneen Ward, Chebyshev centers in spaces of continuous functions . .

Robert Breckenridge Warfield, Jr., The uniqueness of elongations of Abelian

groups...

V. M. Warfield, Existence and adjoint theorems for linear stochastic differential

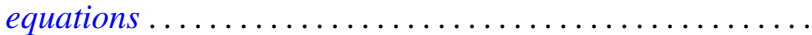

